\title{
NMR Pore Structure and Dynamic Characteristics of Sandstone Caused by Ambient Freeze-Thaw Action
}

\author{
Bo Ke, ${ }^{1}$ Keping Zhou, ${ }^{1}$ Hongwei Deng, ${ }^{1}$ and Feng Bin ${ }^{2}$ \\ ${ }^{1}$ School of Resource and Safety Engineering, Central South University, Changsha, Hunan 410083, China \\ ${ }^{2}$ Hunan Labour Protection Institute of Nonferrous Metals, Changsha, Hunan 410014, China \\ Correspondence should be addressed to Hongwei Deng; denghw208@126.com
}

Received 21 February 2017; Revised 15 May 2017; Accepted 28 May 2017; Published 29 June 2017

Academic Editor: Yuri S. Karinski

Copyright (c) 2017 Bo Ke et al. This is an open access article distributed under the Creative Commons Attribution License, which permits unrestricted use, distribution, and reproduction in any medium, provided the original work is properly cited.

\begin{abstract}
For a deeper understanding of the freeze-thaw weathering effects on the microstructure evolution and deterioration of dynamic mechanical properties of rock, the present paper conducted the nuclear magnetic resonance (NMR) tests and impact loading experiments on sandstone under different freeze-thaw cycles. The results of NMR test show that, with the increase of freezethaw cycles, the pores expand and pores size tends to be uniform. The experimental results show that the stress-strain curves all go through four stages, namely, densification, elasticity, yielding, and failure. The densification curve is shorter, and the slope of elasticity curve decreases as the freeze-thaw cycles increase. With increasing freeze-thaw cycles, the dynamic peak stress decreases and energy absorption of sandstone increases. The dynamic failure form is an axial splitting failure, and the fragments increase and the size diminishes with increasing freeze-thaw cycles. The higher the porosity is, the more severe the degradation of dynamic characteristics is. An increase model for the relationships between the porosity or energy absorption and freeze-thaw cycles number was built to reveal the increasing trend with the freeze-thaw cycles increase; meanwhile, a decay model was built to predict the dynamic compressive strength degradation of rock after repeated freeze-thaw cycles.
\end{abstract}

\section{Introduction}

In geotechnical engineering, rock contains a certain amount of water. Freeze-thaw cycle is a typical weathering process and has strong impacts on the physicomechanical behaviors of rock in the cold regions. Ice phase volume expansion of water within pores produces the freezing force during freeze-thaw weathering [1]. Under this condition, the rock becomes a multiphase medium that includes rock matrix, water, ice, and gas. The freezing force has an important impact on the rock deformation; hence, the stability of rock engineering structures as the freezing force will cause internal damage due to crack development. Due to the significant effects on engineering properties of the rock mass, rock freeze-thaw weathering is crucial in the whole design, construction, and maintenance stages of geotechnical works $[2,3]$.

Freeze-thaw weathering has long been discussed as a major physical deterioration process. Beier and other scholars have verified that the mechanical properties of rock are severely affected by freeze-thaw cycles, leading to the appearance of nonconventional rock failure phenomena [4, 5]. Many experimental studies have been conducted to investigate the deterioration of physical and static mechanical properties of various rocks under different freeze-thaw cycles [6-11], including density, porosity, P-wave velocity, point load strength, elastic modulus, negative Poisson's ratio, and uniaxial compressive strength (UCS).

The frequent freezing and thawing of pore water inside rock expand the cracks and pores and promote the development of new microfractures [12] and thus do great damage to rock engineering [13]. Thus, changes in the internal microstructure are the crucial factor causing the damage of rock after freeze-thaw processes [14]. Also, some advanced technologies such as X-ray computed tomography (X-ray CT), scanning electron microscope (SEM), and nuclear magnetic resonance (NMR) are used to analyze the evolution of the microstructure at the different number of freeze-thaw cycles $[12,15-18]$. 
In fact, because of the extensively existing blasting operation and mechanized construction as well as seismic oscillation, rock engineering disasters often involve rock responses to stress pulses or impact loads, and the corresponding prevention and cure researchers come down to the analyses on dynamic mechanical properties of rock-like materials [19, 20]. For example, in 2013, the slope failure in the Tibet Jiama Mine of China caused by the combined effects of the rock weakening due to freeze-thaw cycles and dynamic loading resulted in the collapse of more than 2 million cubes of rocks and numerous casualties and serious property losses. The weakening of rock excavation structures due to this combined effect is a significant problem in a cold climate such as in the major part of western and northern China. Therefore, it is critical to understand the dynamic characteristics of rocks under the action of the freeze-thaw processes, which is important from both the theoretical point of view and practical engineering applications.

Due to the high loading rate, the mechanical properties of rocks under dynamic load are noticeably different from those under static load after freeze-thaw weathering. Through the above previous analysis of the research results on the mechanical properties of rock under F-T cycles, scholars mainly centered on the physical and statics mechanical properties; only a few works have been published about the dynamic mechanical behaviors of freeze-thaw weathered rock. The microscopic damage characteristics and dynamic mechanical parameters of sandstone subjected to repeated freeze-thaw cycles were investigated from the NMR tests and impact loading tests [17]. Static and dynamic mechanical properties of sedimentary rock after freeze-thaw weathering were obtained from the SEM technique, static compression, and SHPB impact tests [3]. Considering the strain rate effect, a prediction model for the dynamic mechanical degradation of sedimentary rock was proposed after long-term freeze-thaw weathering [19]. Investigations about the effects of freezethaw cycles on the rock's dynamic mechanical properties during the weathering process are far from enough.

In this paper, for a deeper understanding of the freezethaw weathering effects on the microstructure evolution and deterioration of dynamic mechanical properties of rock, first sandstone, a common sedimentary rock, was selected as the test object; then a dynamic compression test on sandstone under different freeze-thaw cycles was carried out using the Split-Hopkinson Pressure Bar (SHPB) system [21], and nuclear magnetic resonance (NMR) technique is used to detect microscopic damage of sandstone. Totally five experimental groups, respectively, that suffered 0, 20, 60, 100, and 140 artificial freeze-thaw cycles were prepared for static compression and dynamic impact tests, respectively, of which 140 freeze-thaw cycles group was used for the NMR tests.

\section{Specimen and Experimental}

2.1. Specimen. The rock specimens are dense, uniform, fineto-medium-grained sandstone with a light yellow color. The yellow color is given by the clay cementation materials. In addition to the off-white color quartz sand and the brown clay fillings, there are many tiny, shiny specks. They are very small grains of muscovite. The specimens are obtained by the water drilling method and then prepared as cylinders with a diameter of $50 \mathrm{~mm}$ and a height of $50 \mathrm{~mm}$. The flatness of the specimens was less than $0.02 \mathrm{~mm}$.

2.2. Static Compressive Tests. In order to compare the static properties with the dynamic characteristics, the static load tests were first carried out using an Instron 1346 hydraulic servo-controlled machine. In this work, three specimens were prepared for the static compressive tests. All tests were conducted on specimens by computerized strain control at a constant loading rate of $0.1 \mathrm{~mm} / \mathrm{min}$. During tests, the axial load was recorded by the machine directly, and the axial strain of the specimen was monitored by a linear variant differential transducer (LVDT).

2.3. Freeze-Thaw Tests. A TDS-300 freeze-thaw cycle testing machine is used in the experiment. In the freeze-thaw test, saturated samples are placed into the freeze-thaw machine and conditioned at $-20^{\circ} \mathrm{C}$ for 4 hours. Then, they are taken out of the freezer and placed in the water at $20^{\circ} \mathrm{C}$, where they are allowed to thaw for 4 hours [8]. All the samples are provided as saturated samples and are divided into 5 groups with 25 samples, and five different numbers of freeze-thaw cycles, $0,20,60,100$, and 140, are selected.

2.4. NMR Tests. The observation of the evolution of microstructural deterioration of rocks is very important to the establishment of equations of deteriorating evolution and deterioration of the mechanical properties of the medium of rocks. Recently, some new techniques make it possible to look into the inner parts of rocks. Here, the technique of nuclear magnetic resonance (NMR) was used to obtain the porosity and pore size distribution.

The hydrogen proton $\left(\mathrm{H}^{+}\right)$is a particle with a positive charge, and proton spin is one of the important properties of the hydrogen proton. Hydrogen proton spin can produce a magnetic field, and magnetic axes directions of protons are random in no external magnetic field. The NMR technique can detect hydrogen nucleus proton and its energy states of water existing in rocks.

A real NMR measurement to determine the microstructure of rock includes several steps. (1) Put the specimens within the NMR instrument; the magnetic axis of a group of protons will be randomly oriented in the absence of a magnetic field. (2) In the presence of the main magnetic field $B_{0}$, hydrogen protons align both with and against the field. Because of the difference in energy between the two alignments, there is slight excess of protons in the lower energy state (those aligned with the field). (3) A 90-degree radiofrequency pulse applied at the resonance frequency causes the protons to flip and align with the higher energy state. (4) After the action of the RF pulse is over, the flipped protons "relax" back to their original alignment at a rate determined by $T_{2}$ relaxation times. The magnetic resonance signal is measured during the much shorter period of $T_{2}$ relaxation [22].

In this work, after the freeze-thaw treatment, NMR tests were conducted on the treated specimens by the AniMR-150 


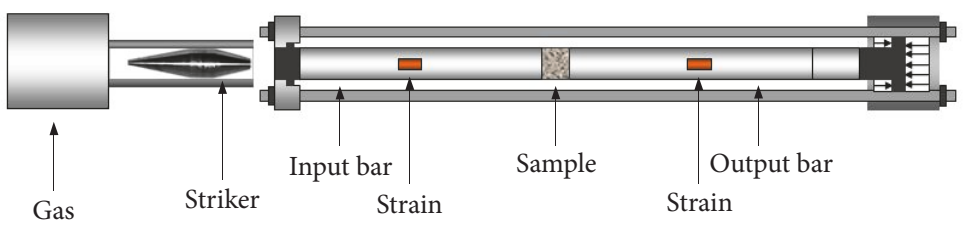

Figure 1: The Split-Hopkinson Pressure Bar test.

NMR imaging system, which is manufactured by Niumag Electric Technology Company, Ltd. in the city of Suzhou. With the NMR signals, the porosity, $T_{2}$ distribution, and NMR image of specimens can be obtained [23].

2.5. Dynamic Compressive Tests. The detailed geometric dimensions of the modified Hopkinson bar shown in Figure 1 were introduced in previous publications [24]. The entire setup consists of the incident and transmitted bar subsystem, striker launcher subsystem, and data processing subsystem. The incident and transmitted bar subsystem is composed of two long elastic bars, that is, an input bar and an output bar. The elastic bars are $2 \mathrm{~m}$ in length and $50 \mathrm{~mm}$ in diameter, with an elastic modulus of $250 \mathrm{GPa}$, Poisson's ratio between 0.25 and 0.3 , and longitudinal wave velocity of $5547 \mathrm{~m} / \mathrm{s}$. Strain gauges are mounted on the middle of the elastic bars to measure the strain histories induced by the stress waves propagating along the elastic bars. The striker launcher subsystem comprises a striker bar, gas tank, pressure vessel, gas switches, and outlet valves [24]. The striker bar has a double-tapered shape and possesses the parameters provided in [25] to produce a half-sine waveform, which can eliminate wave oscillation and reduce wave-dispersion effects [26, 27]. The speed of the striker bar was controlled manually by adjusting the gas pressure in the gas tank. Impact loading tests were carried out at gas pressure of $0.5 \mathrm{MPa}$ and the strain rate at $75 \mathrm{~s}^{-1}$. Before that, gas pressure was selected according to the broken pieces, between 2 and 4 pieces, of standby sample in impulse tests.

Upon impact of a striker bar on an incident bar, an elastic compressive wave is generated within the incident bar, and the time-dependent incident strain $\varepsilon_{i}$ in the pressure bar is measured by the strain gauge. At the incident bar/specimen interface, the wave is partially reflected and partially transmitted. A portion of the incident wave is reflected back along the incident bar as a tensile wave. This reflected strain $\varepsilon_{r}$ can be measured by strain gauge. Transmitted strain $\varepsilon_{t}$ measurements are also taken on the output bar with strain gauge. These strain measurements on the pressure bars are used to determine the stress-strain behavior of the sample [28].

Using the wave signals from the gauges on the incident and transmitted bars by the data processing subsystem, the dynamic stress-strain curves of the samples can be calculated by the 1-wave or 3-wave analysis method through the principle of $1 \mathrm{D}$ wave propagation theory [28]. Using the 3 -wave analysis method [29], strain gauges mounted on the incident bar measure the incident strain $\varepsilon_{i}$ and reflected $\varepsilon_{r}$ strain pulses, and strain gauges mounted on the transmission

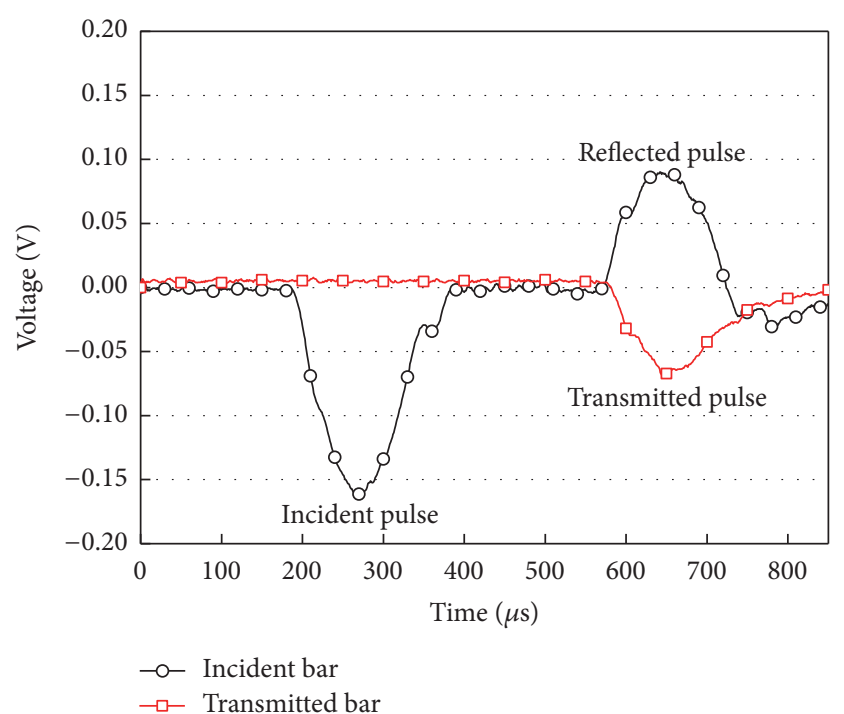

FIGURE 2: Incident wave, reflected wave, and transmitted wave in the bars in the dynamic testing.

bar measure the transmitted $\varepsilon_{t}$ strain pulse (Figure 2), which are used to calculate engineering strain $\varepsilon_{s}$, engineering stress $\sigma_{s}$, and strain rate $\dot{\varepsilon}_{s}$. The formula is as follows [30]:

$$
\begin{aligned}
& \varepsilon_{s}=\frac{c_{b}}{l_{s}} \int\left(-\varepsilon_{i}+\varepsilon_{r}+\varepsilon_{t}\right) d t, \\
& \sigma_{s}=\frac{A E}{2 A_{s}}\left(\varepsilon_{i}+\varepsilon_{r}+\varepsilon_{t}\right), \\
& \dot{\varepsilon}_{s}=\frac{c_{b}}{l_{s}}\left(-\varepsilon_{i}+\varepsilon_{r}+\varepsilon_{t}\right),
\end{aligned}
$$

where $c_{b}$ is the wave velocity of the steel bars, $l_{s}$ is the original length of the sample, $A$ is the cross section area of the bars, $A_{s}$ is the original area of the sample face in contact with the bar, and $E$ is the elastic modulus of the bars.

The dynamic force on one side of the specimen is proportional to the sum of the incident (In) and reflected (Re) stress waves, and the dynamic force on the other side is proportional to the transmitted ( $\mathrm{Tr}$ ) wave. As shown in Figure 3, for a typical dynamic compressive test, the dynamic forces on both ends of sample are almost identical during the dynamic loading history. Therefore, the sample is in dynamic 
TABLE 1: Static mechanical properties of sandstone.

\begin{tabular}{lcccc}
\hline Density $\left(\mathrm{kg} / \mathrm{m}^{3}\right)$ & Wave velocity $(\mathrm{m} / \mathrm{s})$ & UCS $(\mathrm{MPa})$ & Elastic modulus $(\mathrm{GPa})$ & Poisson's ratio \\
\hline 2360 & $3500-4200$ & 75.04 & 15.7 & 0.2 \\
\hline
\end{tabular}

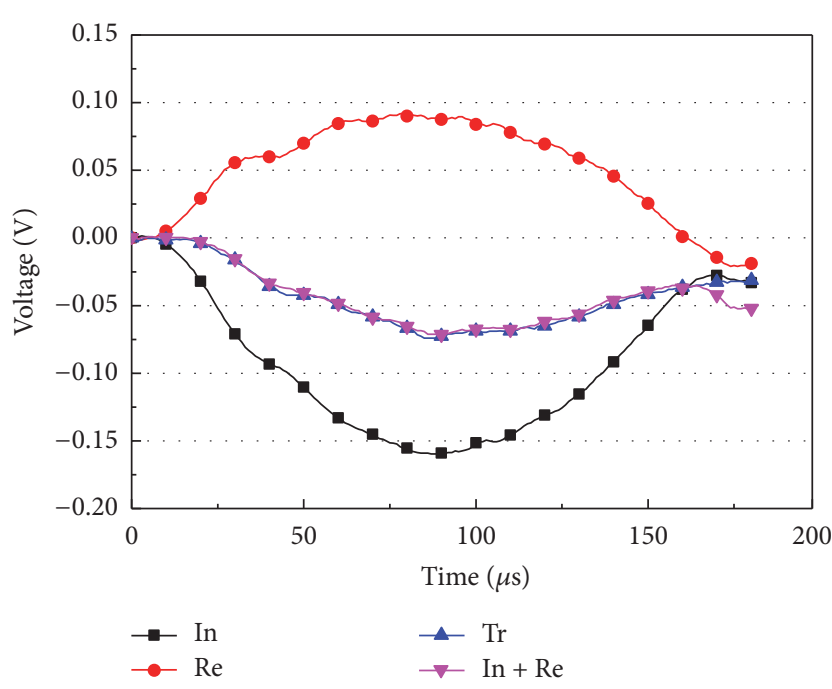

FIgURE 3: Dynamic force equilibrium for a typical dynamic compressive test.

stress equilibrium in this SPHB system [24], and $\varepsilon_{i}+\varepsilon_{r}=\varepsilon_{t}$; then the strain, stress, and strain rate are given as follows [31]:

$$
\begin{aligned}
& \varepsilon_{s}=\frac{c_{b}}{l_{s}} \int 2 \varepsilon_{r}, \\
& \sigma_{s}=\frac{A E}{A_{s}} \varepsilon_{t}, \\
& \dot{\varepsilon}_{s}=\frac{2 c_{b}}{l_{s}} \varepsilon_{r} .
\end{aligned}
$$

\section{Results and Discussion}

3.1. Static Properties with No Freeze-Thaw Cycle. The average material properties were determined for the five samples summarized in Table 1.

Typically, the static stress-strain curve can be divided into four phases, as shown in Figure 4. The threshold strength from the densification stage (OA) to the elasticity stage $(\mathrm{AB})$ is approximately $21 \mathrm{MPa}$. The threshold strength from the elasticity stage $(\mathrm{AB})$ to the yielding stage $(\mathrm{BC})$ is approximately $56.5 \mathrm{MPa}$.

\subsection{NMR Pore Structure Characteristics}

3.2.1. $T_{2}$ Distribution. The transverse relaxation time $T_{2}$ of pore fluid is related to the size of pores in rocks, and the relaxation time is proportional to the size of pores [23]. The peak and area of $T_{2}$ distribution demonstrate the concentrative degree and amount of pores of different size. Therefore,

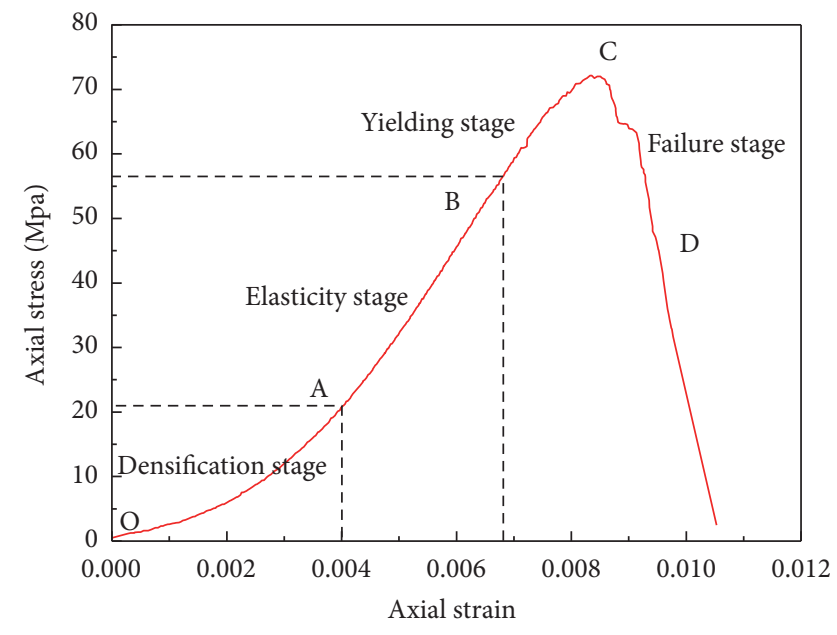

FIGURE 4: Static stress-strain curves of sandstone.

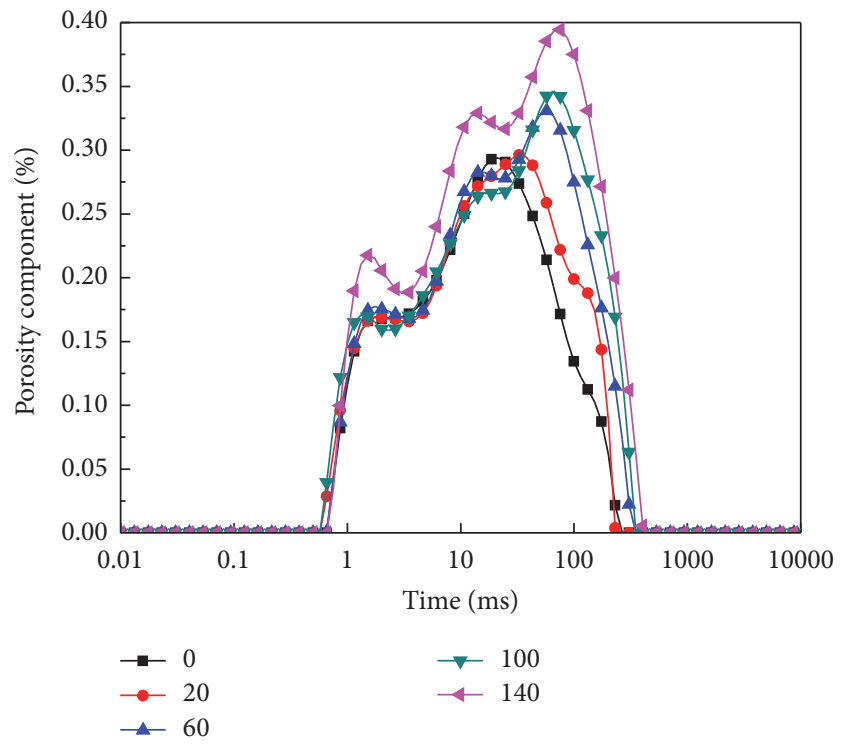

Figure 5: The $T_{2}$ distribution variation of sandstone under the number of freeze-thaw cycles from 0 to 140 .

$T_{2}$ distributions can be used to analyze the expansion and extension of pores in rocks to study the trend of rock damage. Figure 5 shows $T_{2}$ distributions of the sandstone after treatment by different number of freeze-thaw cycles (from 0 to 140). These distributions essentially describe the proportion of pores with different sizes in a multiscale pore structure.

It can be seen from Figure 5 that the $T_{2}$ distribution has two peak values at small number of freeze-thaw cycles, but it gradually evolves into three peak values after the treatment 
TABLE 2: Porosity variation of sandstone after different freeze-thaw cycles.

\begin{tabular}{lcccccc}
\hline \multirow{2}{*}{ Piece number } & \multicolumn{5}{c}{ Saturated rock porosity after different freeze-thaw cycles\% } & \multirow{2}{*}{ Percentage increase in porosity\% } \\
& 0 & 20 & 60 & 100 & 140 & 58.18 \\
$140-1$ & 7.207 & 8.018 & 9.362 & 9.76 & 11.400 & 12.518 \\
$140-2$ & 8.156 & 9.317 & 9.842 & 10.84 & 11.227 & 49.32 \\
$140-3$ & 7.519 & 8.383 & 9.326 & 10.264 & 11.668 & 43.31 \\
$140-4$ & 8.142 & 9.572 & 10.146 & 10.797 & 12.202 & 54.26 \\
$140-5$ & 7.910 & 8.417 & 9.728 & 10.845 & 11.803 & 51.71 \\
\hline Average value & 7.787 & 8.741 & 9.681 & 10.501 & \\
\hline
\end{tabular}

of 60 freeze-thaw cycles. With the increase of freeze-thaw cycles, the $T_{2}$ distribution shifts to the right, indicating that large size pores increase. This suggests that the pore structure has developed from small size to large size and the internal damage accumulates gradually. The change of $T_{2}$ distributions at $60-100$ freeze-thaw cycles is small, which suggests that, within this range of freeze-thaw process, the pore structure changes are constrained by the cohesion between crystal grains and the development of pore size enlargement is restricted and the degree of freeze-thaw damage is small.

3.2.2. Variation of Porosity. The porosity of the rock has a significant influence on its physical and mechanical properties. Therefore, it is important to investigate the changes of porosity due to freeze-thaw processes and their effects on the damage characteristics of rock. Table 2 lists the variation in the porosity of sandstone after treatment at different number of freeze-thaw cycles. As can be seen from Table 2, the porosity of sandstone samples increases with the increase in the number of freeze-thaw cycles, with an average increase of $51.71 \%$ when the number of freeze-thaw cycles reaches 140 . This increasing trend is consistent with the observation of pore structure changes described in the previous section. In the freezing phase, water in pores turns into ice and the corresponding volume increases, which results in the frost-heaving stress, forcing the micropores to expand. In the thawing phase, the ice turns into water, which then migrates inside the rock, causing dissolution of minerals between internal pores. Consequently, these freeze-thaw cycles increase the damage of rock matrix, increase the pore sizes, and cause microcracks to appear.

Figure 6 further presents the porosity of specimens under different freeze-thaw cycles. The regression analysis reveals that the relationship between the dynamic compressive strength and freeze-thaw cycles can be determined using the following equations:

$$
\begin{aligned}
& w_{N}=\ln w_{0} \ln (N+a)^{b}, \\
& \quad a=1.073, \quad b=33.060, R^{2}=0.948,
\end{aligned}
$$

where $w_{N}$ is the porosity after $N$ freeze-thaw cycles, $w_{0}$ is the original porosity, and $a$ and $b$ are the constants. It can be seen that, compared with the original average porosity of sandstone which is $7.787 \%$, the average porosity increases to $8.741 \%, 9.681 \%, 10.501 \%$, and $11.803 \%$ after $20,60,100$, and

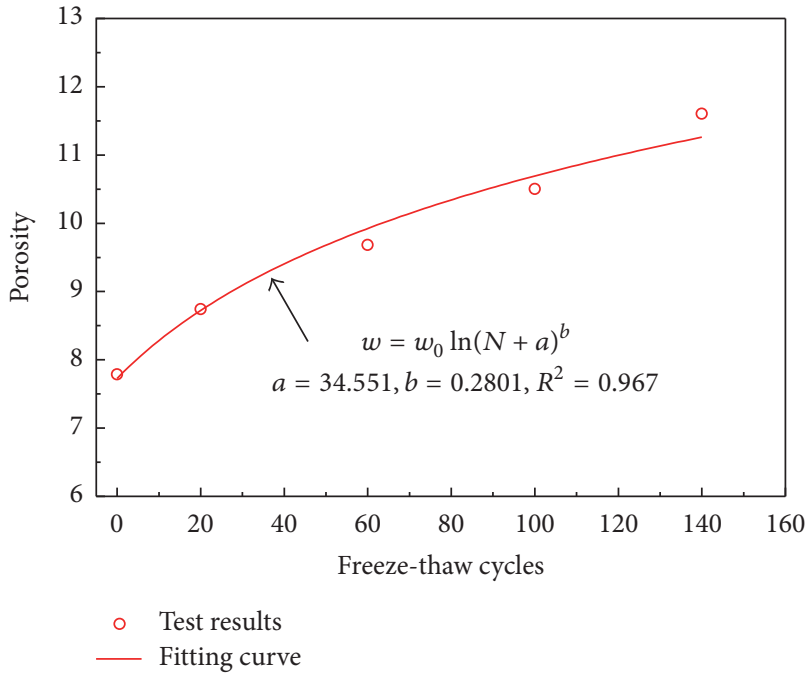

FIGURE 6: The relationship of porosity and freeze-thaw cycles.

140 freeze-thaw cycles with an increase of $12.25 \%, 24.32 \%$, $34.85 \%$, and $51.71 \%$, respectively.

3.3. Freeze-Thaw Cycles Effect on Dynamic Compressive Properties of Sandstone. According to (2), the complete stressstrain curves under dynamic loadings and different freezethaw cycles can be obtained. Table 3 gives the parameters of specimens under different freeze-thaw cycles in the dynamic compressive tests, and Figure 7 presents the dynamic stressstrain curves of sandstone under different freeze-thaw cycles.

As is shown in Figure 7, the complete stress-strain curves all go through four stages, namely, densification, elasticity, yielding, and failure, like the static stress-strain curves. With the number of freeze-thaw cycles increasing, the slope of densification and elasticity curve decreases, the peak stress decreases, and the peak strain increases, showing that the internal damage of sandstone gradually accumulates and the crack increases under the freeze-thaw cycles, resulting in the decrease of the initial modulus and strength.

Besides, many decay models [32-36] were built by scholars to analyze the durability of rocks that suffered long-term freeze-thaw weathering. Mutlutürk et al. [32] proposed a decay model that uses the decay constant $(\lambda)$ parameters to express the disintegration rate of rock. Considering the 
TABLE 3: Specimens parameters in dynamic compressive tests under different freeze-thaw cycles.

\begin{tabular}{|c|c|c|c|c|c|}
\hline \multirow{2}{*}{ Specimen group and number } & \multirow{2}{*}{ Diameter/mm } & \multirow{2}{*}{ Height/mm } & \multicolumn{2}{|c|}{ Strength/MPa } & \multirow{2}{*}{ Strain rate $/ \mathrm{s}^{-1}$} \\
\hline & & & Tested & Average & \\
\hline \multicolumn{6}{|l|}{0 freeze-thaw cycles } \\
\hline 1 & 51.66 & 49.76 & 96.95 & \multirow{5}{*}{98.08} & 77.45 \\
\hline 2 & 51.90 & 49.80 & 99.93 & & 73.44 \\
\hline 3 & 52.09 & 49.80 & 98.60 & & 73.28 \\
\hline 4 & 51.94 & 49.80 & 98.82 & & 73.23 \\
\hline 5 & 52.15 & 49.80 & 96.12 & & 75.43 \\
\hline \multicolumn{6}{|l|}{20 freeze-thaw cycles } \\
\hline 1 & 52.03 & 49.76 & 94.31 & \multirow{5}{*}{93.59} & 75.03 \\
\hline 2 & 51.70 & 49.80 & 92.52 & & 77.24 \\
\hline 3 & 50.77 & 49.82 & 94.19 & & 78.09 \\
\hline 4 & 51.00 & 49.80 & 93.83 & & 74.58 \\
\hline 5 & 51.86 & 49.72 & 93.12 & & 81.01 \\
\hline \multicolumn{6}{|l|}{60 freeze-thaw cycles } \\
\hline 1 & 51.49 & 49.82 & 88.05 & \multirow{5}{*}{87.83} & 75.93 \\
\hline 2 & 50.90 & 49.80 & 88.97 & & 78.76 \\
\hline 3 & 51.00 & 49.80 & 86.23 & & 76.04 \\
\hline 4 & 51.69 & 49.76 & 87.24 & & 75.42 \\
\hline 5 & 51.91 & 49.78 & 88.64 & & 79.68 \\
\hline \multicolumn{6}{|l|}{100 freeze-thaw cycles } \\
\hline 1 & 51.95 & 49.74 & 82.81 & \multirow{5}{*}{83.69} & 73.80 \\
\hline 2 & 51.79 & 49.80 & 83.88 & & 77.59 \\
\hline 3 & 51.74 & 49.80 & 83.43 & & 69.60 \\
\hline 4 & 51.78 & 49.80 & 83.47 & & 76.15 \\
\hline 5 & 52.23 & 49.76 & 84.88 & & 72.47 \\
\hline \multicolumn{6}{|l|}{140 freeze-thaw cycles } \\
\hline 1 & 51.90 & 51.92 & 78.05 & \multirow{5}{*}{77.03} & 70.29 \\
\hline 2 & 51.96 & 51.94 & 77.79 & & 74.59 \\
\hline 3 & 51.78 & 51.80 & 75.61 & & 73.96 \\
\hline 4 & 51.78 & 51.70 & 76.36 & & 74.89 \\
\hline 5 & 51.76 & 51.80 & 77.33 & & 75.96 \\
\hline
\end{tabular}

dynamic strain rate effect, Wang et al. [19] proposed a prediction model for the dynamic mechanical degradation of sedimentary rock after freeze-thaw weathering based on this decay model. Following this relation, to fully describe the dependence of the dynamic compressive strength of rock on the static compressive strength, strain rate, and freeze-thaw cyclic number, a new decay equation in exponential form is proposed based on some empirical formula [37]:

$$
\mathrm{UCS}_{N}=\mathrm{UCS}_{0} e^{-\lambda N}\left[1+\alpha *(\dot{\varepsilon})^{\beta}\right] \text {, }
$$

where $\mathrm{UCS}_{N}$ is the dynamic UCS of rock after $N$ freeze-thaw cycles, $\mathrm{UCS}_{0}$ is the original dynamic UCS of rock, $\dot{\varepsilon}$ is the strain rate, $\lambda, \alpha$, and $\beta$ are the constants, and $N$ is the freezethaw cycles number.

The physical meaning of each term of (4) is justified as follows. On the right-hand side of (4), the second term in the product describes the freeze-thaw cycles damage and the third term is the strain rate. According to the physical meanings of each term, with this analysis method, the fitting curves and fitting parameters are shown in Figure 8. It can be seen that the equations match the trend of the data well. Compared with the original average peak stress of sandstone which is $98.08 \mathrm{MPa}$, the average peak stress reduces to 93.59 $\mathrm{MPa}, 87.83 \mathrm{MPa}, 83.69 \mathrm{MPa}$, and 77.03 $\mathrm{MPa}$ after 20, 60, 100 , and 140 freeze-thaw cycles with a loss of $3.76 \%, 9.91 \%$, $13.94 \%$, and $21.42 \%$, respectively.

\subsection{Freeze-Thaw Cycles Effect on Dynamic Failure Characteristic}

3.4.1. Freeze-Thaw Cycles Effect on Energy Absorption of Sandstone. In the SHPB experiments, the essence of sample damage is energy transmission. It is impossible to acquire directly the amount of energy dissipation of the damage process of sandstone. When the incident bar is struck by the striker bar, the energy spreads in the incident bar as the form of an elastic compressive wave. Then the wave is propagated on the interface of the incident bar and sample; the energy is partially reflected and partially transmitted into the sample. The energy which is transmitted to the sample is divided into 


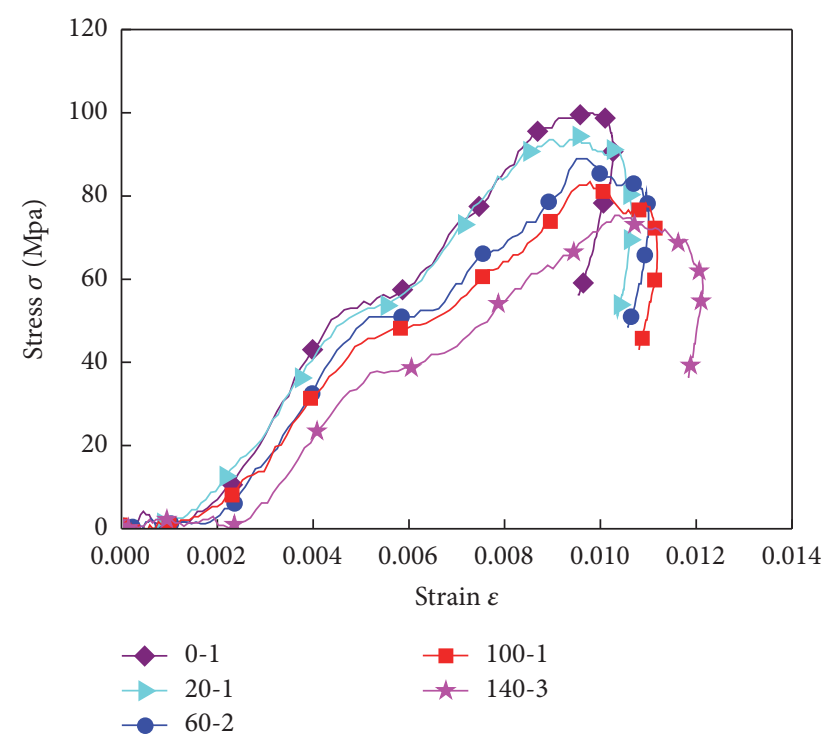

Figure 7: The dynamic stress-strain curves of sandstone under different freeze-thaw cycles.

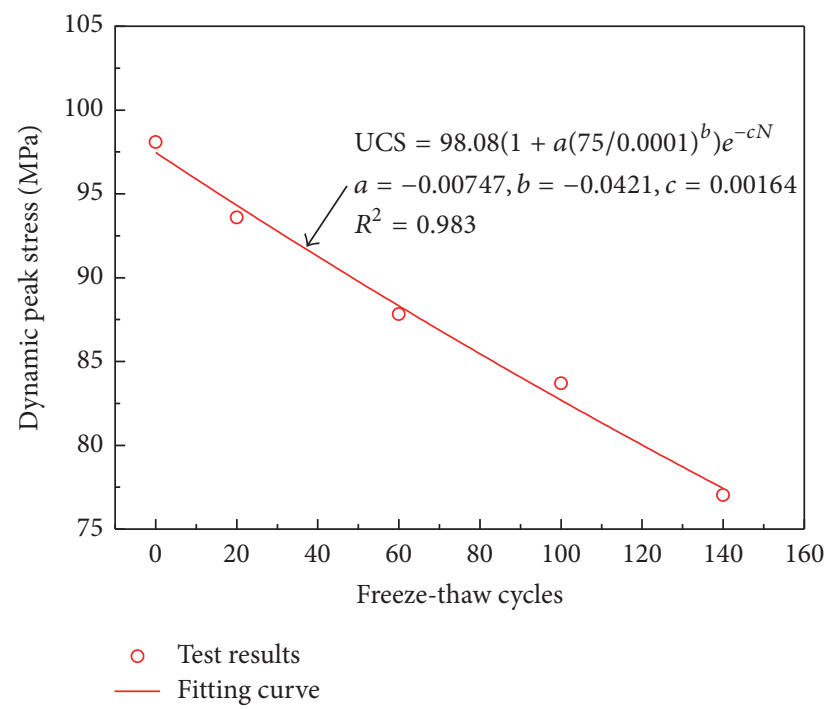

FIGURE 8: Relationship between dynamic peak stress and number of freeze-thaw cycles.

two parts: one part of energy damages the sample and the other part of energy generates reflection and transmission on the interface of sample and output bar. Therefore the sample energy absorption $\left(W_{L}\right)$ can be calculated indirectly by the relationship of the energy of the incident stress wave $\left(W_{I}\right)$, the energy of the reflected stress wave $\left(W_{R}\right)$, and the energy of the transmitted stress wave $\left(W_{T}\right)$, and the equation is as follows [38]:

$$
\begin{aligned}
W_{L} & =W_{I}-W_{R}-W_{T} \\
& =A c_{b} E \int_{0}^{T}\left[\varepsilon_{i}^{2}(t)-\varepsilon_{r}^{2}(t)-\varepsilon_{t}^{2}(t)\right] d t,
\end{aligned}
$$

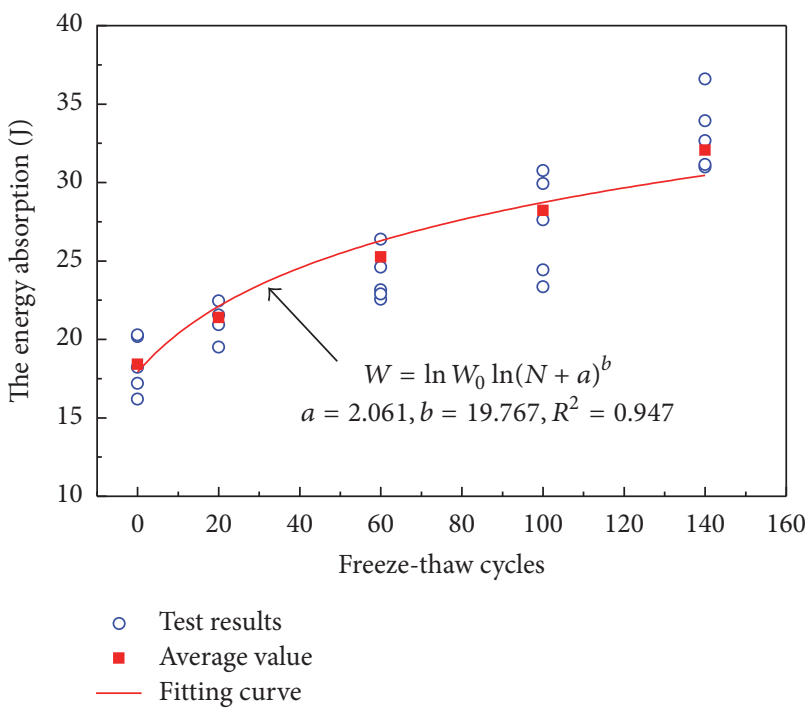

FIGURE 9: Relationship between energy absorption and number of freeze-thaw cycles.

where $T$ represents the moment that the sandstone is completely damaged.

According to the calculation principle of energy absorption, Figure 9 shows the relationship between energy absorption and the number of freeze-thaw cycles. The energy absorption of sandstone shows a significant increase with the freeze-thaw cycles increasing.

The energy absorption in rocks depends on many factors: not only the porosity but also the size of the rock particles, cement, saturation, and so on. When the other rock properties are the same, the internal pores and cracks of sandstone increase gradually as the freeze-thaw cycles increase. However, the energy absorption in rock failure is closely related to the internal damage characteristics. In the dynamic test, the stages of cracks growth, propagation, initiation, and expansion in the rock all need to absorb energy from the incident stress wave, and this is an irreversible energy dissipation process. The greater the porosity of the rock, the lower the strength; the damage of the rock will be more severe in the dynamic test, which results in more energy absorption in the process of rock failure.

Figure 9 also further presents the energy absorption of specimens under different freeze-thaw cycles. The regression analysis reveals that the relationship between the energy absorption and freeze-thaw cycles can be determined by the following equation:

$$
\begin{aligned}
& W_{N}=\ln W_{0} \ln (N+a)^{b}, \\
& \quad a=2.061, b=19.767, R^{2}=0.947,
\end{aligned}
$$

where $W_{N}$ is the energy absorption after $N$ freeze-thaw cycles, $W_{0}$ is the original energy absorption of sandstone, and $a$ and $b$ are the constants. The average energy absorption at 0 freeze-thaw cycles is $18.41 \mathrm{~J}$. After 20,60, 100, and 140 freezethaw cycles, the average energy absorption of sample is $21.40 \mathrm{~J}, 25.26 \mathrm{~J}, 28.21 \mathrm{~J}$, and $32.06 \mathrm{~J}$, with an increment of 

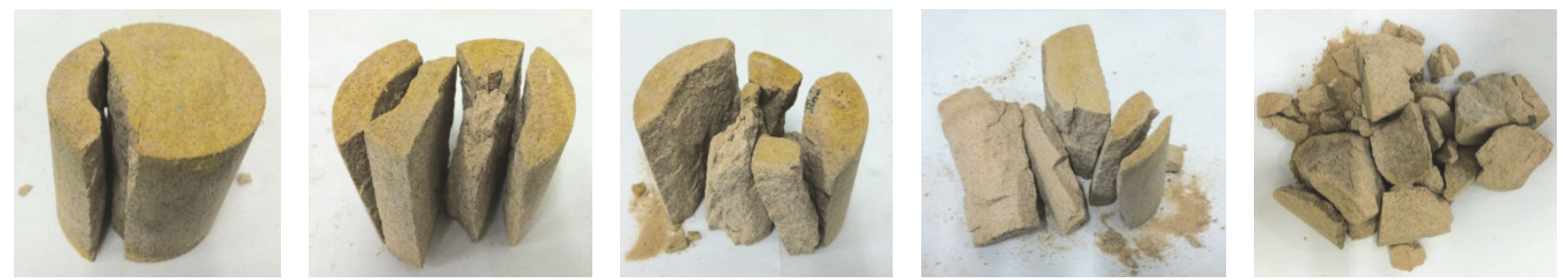

FIGURE 10: Failure forms under different freeze-thaw cycles.

$16.23 \%, 37.18 \%, 53.25 \%$, and $74.13 \%$, respectively, compared to 0 freeze-thaw cycles.

3.4.2. Dynamic Failure Forms. In the impacting tests, the tensile cracks nucleate from the preexisting flaws in the direction of the maximum tensile stress, and the failure form is mainly the axial splitting failure. The fractured surface parallels the axial direction, and it produces 2-3 larger blocks. The surface of the section particles is free of scratches. It is considered that the specimen has a Poisson effect under longitudinal stress, which results in a transverse tensile strain and then breaking in the transverse tensile.

Figure 10 shows the failure forms of sandstone with impact loading under different freeze-thaw cycles. The size and amount of rock fragments generated in the experiment change with different freeze-thaw cycle numbers. As the number of freeze-thaw cycles increases, the breakage degree increases, the size significantly diminishes, and the amount increases, showing a strong correlation with the number of freeze-thaw cycles. When the number of freeze-thaw cycles is low, the rock fragments are intact or incomplete, deformation is smaller, and the stress is higher. With increasing freezethaw cycles, the rock fragments are more broken completely, the strain increases, and the stress decreases. When the number of freeze-thaw cycles is 140, the dynamic failure becomes more and more intensive. The main reason is that, with increasing freeze-thaw cycles, the number of bulk mass pores increases and presents centralized distribution, resulting in increasing the number of fragments and decreasing the size obviously.

3.5. Relationship between NMR Porosity and Dynamic Characteristics of Sandstone. Rock is a nonhomogeneous and brittle geological material that is composed of various mineral grains and cement. The mineral grains size and composition, cement strength, defects and distribution, and density are the main rock properties which have the greatest effect on the degree of rock damage after freeze-thaw cycles [7]. The higher the strength, the denser the mineral grains and the higher the cement strength, and the smaller the porosity of the rock, the smaller the effect of the freeze-thaw cycle and, reversely, the greater the effect of the freeze-thaw cycle. Therefore, the deterioration of the high strength and dense rock (e.g., the granite and fine-grained sandstone) is less after freeze-thaw cycles [39], while the damage of the low strength and mediumto-coarse-grained rock (e.g., the medium-to-coarse-grained sandstone, limestone, and mudstone) is severe after freezethaw cycle; even some rocks have decomposed under less than 15 freeze-thaw cycles [7]. For the same rock, under the same conditions, the number of freeze-thaw cycles will be the decisive factor for the freeze-thaw damage of rock.

When a rock goes through a freeze-thaw cycle, it undergoes the extension, expansion, and connection of new microcracks and original cracks. The freeze-thaw cycles affect rock damage in 3 ways: (1) expansion when water changes to ice: the pore water freezes and expands by 9 to $10 \%$, exerting stress on the pore wall and when this stress exceeds the tensile strength of the rock, cracking occurs [1]; (2) formation of ice lens or wedge: the ice lenses act like wedges which promote crack initiation and propagation; and (3) hydraulic pressure: as ice grows in a pore or other spaces, owing to the expansion associated with freezing, unfrozen water is expelled from the space $[1,40]$. With the increasing number of freeze-thaw cycles, the rock porosity gradually increases, and the cohesion between the mineral grains gradually decreases. Therefore, the variation of porosity can be used to characterize the deterioration of dynamic properties of rock and the number of freeze-thaw cycles after freeze-thaw cycles.

From the above discussions, we can use the decay equation of (4) to reveal the relationship between the dynamic strength and porosity.

$$
\mathrm{UCS}_{d}=\mathrm{UCS}_{0} e^{-\lambda w}\left[1+\alpha *(\dot{\varepsilon})^{\beta}\right]
$$

where $\mathrm{UCS}_{d}$ is the dynamic UCS of rock, $\mathrm{UCS}_{0}$ is the original dynamic UCS of rock, $\dot{\varepsilon}$ is the strain rate, $\lambda, \alpha$, and $\beta$ are the constants, and $w$ is the porosity. With this analysis method, the fitting curves and fitting parameters are shown in Figure 11. It can be seen that the equations match the trend of the data well.

\section{Conclusions}

In this study, the NMR signals of sandstone specimens after freeze-thaw cycles were obtained and the effect of freeze-thaw cycles on dynamic properties of rock under the strain rate $\left(75 \mathrm{~s}^{-1}\right)$ was experimentally studied using a SHPB system. The following conclusions can be drawn from this study.

(1) The NMR signals analysis indicated that, with the increase of freeze-thaw cycles, the porosity of sandstone increases, and the evolution of pores size tends to be uniform. 


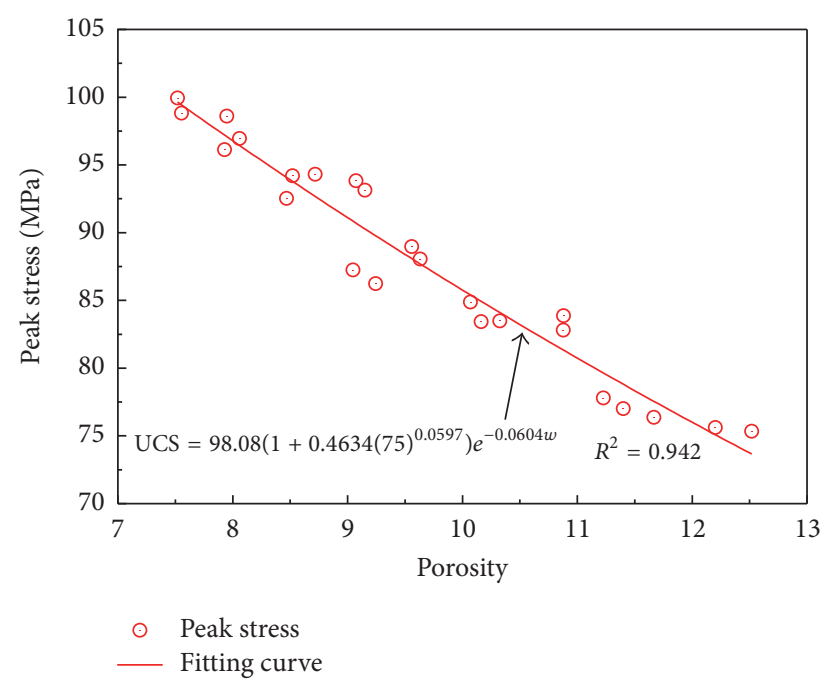

FIGURE 11: The relationship of NMR porosity and dynamic characteristics of sandstone.

(2) The stress-strain curves all go through four stages and the densification curve is shorter. With increasing freezethaw cycles, the dynamic peak stress decreases and the energy absorption increases.

(3) The failure form of sandstones is mainly axial splitting failure under impact loading. With increasing freeze-thaw cycles, the breakage degree increases, and the size diminishes significantly.

(4) An increase model for the relationships between the porosity or energy absorption and freeze-thaw cycles number was built in the form of (3) to reveal the increasing trend after repeated freeze-thaw cycles. Meanwhile, a decay model was built in the form of (4) to predict the dynamic compressive strength degradation of rock after repeated freeze-thaw cycles.

\section{Conflicts of Interest}

The authors declare that they have no conflicts of interest.

\section{Acknowledgments}

The research presented in this paper was jointly supported by the National Natural Science Foundation of China (Grant nos. 51474252 and 41502327) and the Innovation Driven Plan of Central South University (Grant no. 2015CX005). The first author would like to acknowledge the Chinese Scholarship Council for financial support to the joint Ph.D. at the University of Adelaide.

\section{References}

[1] T. C. Chen, M. R. Yeung, and N. Mori, "Effect of water saturation on deterioration of welded tuff due to freeze-thaw action," Cold Regions Science and Technology, vol. 38, no. 2-3, pp. 127-136, 2004.
[2] S. V. Alavi Nezhad Khalil Abad, A. Tugrul, C. Gokceoglu, and D. Jahed Armaghani, "Characteristics of weathering zones of granitic rocks in Malaysia for geotechnical engineering design," Engineering Geology, vol. 200, pp. 94-103, 2016.

[3] P. Wang, J. Xu, S. Liu, H. Wang, and S. Liu, "Static and dynamic mechanical properties of sedimentary rock after freeze-thaw or thermal shock weathering," Engineering Geology, vol. 210, pp. 148-157, 2016.

[4] N. A. Beier and D. C. Sego, "Cyclic freeze-thaw to enhance the stability of coal tailings," Cold Regions Science and Technology, vol. 55, no. 3, pp. 278-285, 2009.

[5] S. Proskin, D. Sego, and M. Alostaz, "Freeze-thaw and consolidation tests on Suncor mature fine tailings (MFT)," Cold Regions Science and Technology, vol. 63, no. 3, pp. 110-120, 2010.

[6] Y. Inada and K. Yokota, "Some studies of low temperature rock strength," International Journal of Rock Mechanics and Mining Sciences \& Geomechanics Abstracts, vol. 21, pp. 145-153.

[7] D. T. Nicholson and F. H. Nicholson, "Physical deterioration of sedimentary rocks subjected to experimental freeze-thaw weathering," Earth Surface Processes and Landforms, vol. 25, no. 12, pp. 1295-1307, 2000.

[8] X. Tan, W. Chen, J. Yang, and J. Cao, "Laboratory investigations on the mechanical properties degradation of granite under freeze-thaw cycles," Cold Regions Science and Technology, vol. 68, no. 3, pp. 130-138, 2011.

[9] H. Yavuz, "Effect of freeze-thaw and thermal shock weathering on the physical and mechanical properties of an andesite stone," Bulletin of Engineering Geology and the Environment, vol. 70, no. 2, pp. 187-192, 2011.

[10] L. Hua, N. Fu-Jun, X. Zhi-Ying, L. Zhan-Ju, and X. Jian, "Acoustic experimental study of two types of rock from the Tibetan Plateau under the condition of freeze-thaw cycles," Sciences in Cold and Arid Regions, vol. 4, no. 1, pp. 21-27, 2012.

[11] M. Fener and I. Ince, "Effects of the freeze-thaw (F-T) cycle on the andesitic rocks (Sille-Konya/Turkey) used in construction building," Journal of African Earth Sciences, vol. 109, pp. 96-106, 2015.

[12] J. Park, C.-U. Hyun, and H.-D. Park, "Changes in microstructure and physical properties of rocks caused by artificial freeze-thaw action," Bulletin of Engineering Geology and the Environment, vol. 74, no. 2, pp. 555-565, 2015.

[13] L. M. O. Sousa, L. M. Suárez del Río, L. Calleja, V. G. Ruiz de Argandoña, and A. Rodríguez Rey, "Influence of microfractures and porosity on the physico-mechanical properties and weathering of ornamental granites," Engineering Geology, vol. 77, no. 1-2, pp. 153-168, 2005.

[14] N. Matsuoka, "Mechanisms of rock breakdown by frost action: An experimental approach," Cold Regions Science and Technology, vol. 17, no. 3, pp. 253-270, 1990.

[15] F. Gao, Q. Wang, H. Deng, J. Zhang, W. Tian, and B. Ke, "Coupled effects of chemical environments and freeze-thaw cycles on damage characteristics of red sandstone," Bulletin of Engineering Geology and the Environment, pp. 1-10, 2016.

[16] V. G. Ruiz De Argandoña, A. Rodríguez Rey, C. Celorio, L. M. Suarez Del Río, L. Calleja, and J. Llavona, "Characterization by Computed X-ray tomography of the evolution of the pore structure of a dolomite rock during freeze-thaw cyclic tests," Physics and Chemistry of the Earth, Part A: Solid Earth and Geodesy, vol. 24, no. 7, pp. 633-637, 1999.

[17] K.-P. Zhou, B. Li, J.-L. Li, H.-W. Deng, and F. Bin, "Microscopic damage and dynamic mechanical properties of rock under 
freeze-thaw environment," Transactions of Nonferrous Metals Society of China (English Edition), vol. 25, no. 4, Article ID 63723, pp. 1254-1261, 2015.

[18] J.-L. LI, K.-P. ZHOU, W.-J. LIU, and H.-W. DENG, "NMR research on deterioration characteristics of microscopic structure of sandstones in freeze-thaw cycles," Transactions of Nonferrous Metals Society of China (English Edition), vol. 26, no. 11, pp. 2997-3003, 2016.

[19] P. Wang, J. Xu, S. Liu, S. Liu, and H. Wang, "A prediction model for the dynamic mechanical degradation of sedimentary rock after a long-term freeze-thaw weathering: Considering the strain-rate effect," Cold Regions Science and Technology, vol. 131, pp. 16-23, 2016.

[20] Q. B. Zhang and J. Zhao, "A review of dynamic experimental techniques and mechanical behaviour of rock materials," Rock Mechanics and Rock Engineering, vol. 47, no. 4, pp. 1411-1478, 2014.

[21] Z. Zhou, X. Cai, W. Cao, X. Li, and C. Xiong, "Influence of water content on mechanical properties of rock in both saturation and drying processes," Rock Mechanics and Rock Engineering, vol. 49, no. 8, pp. 3009-3025, 2016.

[22] R. R. Edelman and S. Warach, "Magnetic resonance imaging," The New England Journal of Medicine, vol. 328, no. 10, pp. 708716, 1993.

[23] O. Mohnke and B. Hughes, "Jointly deriving NMR surface relaxivity and pore size distributions by NMR relaxation experiments on partially desaturated rocks," Water Resources Research, vol. 50, no. 6, pp. 5309-5321, 2014.

[24] X. Li, Z. Zhou, T.-S. Lok, L. Hong, and T. Yin, "Innovative testing technique of rock subjected to coupled static and dynamic loads," International Journal of Rock Mechanics and Mining Sciences, vol. 45, no. 5, pp. 739-748, 2008.

[25] X. B. Li, T. S. Lok, and J. Zhao, "Dynamic characteristics of granite subjected to intermediate loading rate," Rock Mechanics and Rock Engineering, vol. 38, no. 1, pp. 21-39, 2005.

[26] X. B. Li, T. S. Lok, J. Zhao, and P. J. Zhao, "Oscillation elimination in the Hopkinson bar apparatus and resultant complete dynamic stress-strain curves for rocks," International Journal of Rock Mechanics and Mining Sciences, vol. 37, no. 7, pp. 1055-1060, 2000.

[27] T. S. Lok, X. B. Li, D. Liu, and P. J. Zhao, "Testing and response of large diameter brittle materials subjected to high strain rate," Journal of Materials in Civil Engineering, vol. 14, no. 3, pp. 262269, 2002.

[28] G. T. GrayIII, "Classic split-hopkinson pressure bar testing," in Asm handbook, 8. Mechanical testing and evaluation, A. H. Committee, Ed., pp. 1027-1068, ASM International: Novelty edition.

[29] J. M. Lifshitz and H. Leber, "Data processing in the split Hopkinson pressure bar tests," International Journal of Impact Engineering, vol. 15, no. 6, pp. 723-733, 1994.

[30] C. Zou and L. N. Y. Wong, "Experimental studies on cracking processes and failure in marble under dynamic loading," Engineering Geology, vol. 173, pp. 19-31, 2014.

[31] D. J. Frew, M. J. Forrestal, and W. Chen, "A split hopkinson pressure bar technique to determine compressive stress-strain data for rock materials," Experimental Mechanics, vol. 41, no. 1, pp. 40-46, 2001.

[32] M. Mutlutürk, R. Altindag, and G. Türk, "A decay function model for the integrity loss of rock when subjected to recurrent cycles of freezing-thawing and heating-cooling," International
Journal of Rock Mechanics and Mining Sciences, vol. 41, no. 2, pp. 237-244, 2004.

[33] F. Bayram, "Predicting mechanical strength loss of natural stones after freeze-thaw in cold regions," Cold Regions Science and Technology, vol. 83-84, pp. 98-102, 2012.

[34] Q. Liu, S. Huang, Y. Kang, and X. Liu, "A prediction model for uniaxial compressive strength of deteriorated rocks due to freeze-thaw," Cold Regions Science and Technology, vol. 120, pp. 96-107, 2015.

[35] I. Ince and M. Fener, "A prediction model for uniaxial compressive strength of deteriorated pyroclastic rocks due to freezethaw cycle," Journal of African Earth Sciences, vol. 120, pp. 134140, 2016.

[36] H. Jia, W. Xiang, and M. Krautblatter, "Quantifying Rock Fatigue and Decreasing Compressive and Tensile Strength after Repeated Freeze-Thaw Cycles," Permafrost and Periglacial Processes, vol. 26, no. 4, pp. 368-377, 2015.

[37] Z. Zhou, X. Cai, L. Chen, W. Cao, Y. Zhao, and C. Xiong, "Influence of cyclic wetting and drying on physical and dynamic compressive properties of sandstone," Engineering Geology, vol. 220, pp. 1-12, 2017.

[38] S. Liu and J. Y. Xu, "Study on dynamic characteristics of marble under impact loading and high temperature," International Journal of Rock Mechanics and Mining Sciences, vol. 62, pp. 5158, 2013.

[39] A. C. Inigo, M. A. Vicente, and V. Rives, "Weathering and decay of granitic rocks: its relation to their pore network," Mechanics of Materials, vol. 32, no. 9, pp. 555-560, 2000.

[40] H. Oshita and T.-A. Tanabe, "Water migration phenomenon in concrete in postpeak region," Journal of Engineering Mechanics, vol. 126, no. 6, pp. 573-581, 2000. 


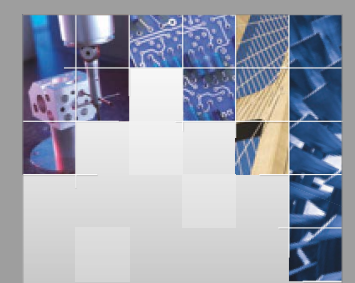

\section{Enfincering}
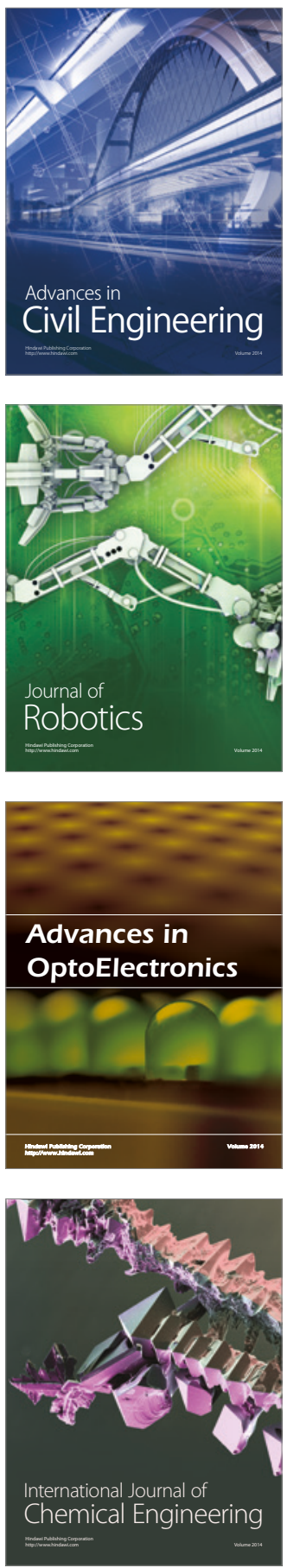

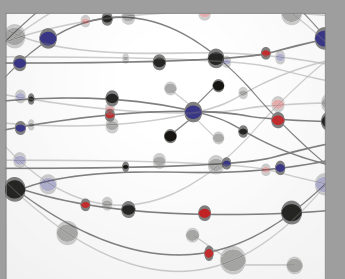

The Scientific World Journal

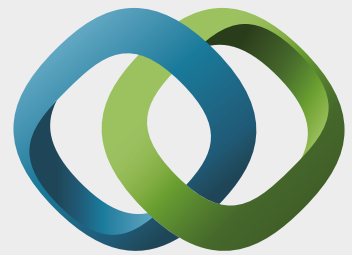

\section{Hindawi}

Submit your manuscripts at

https://www.hindawi.com
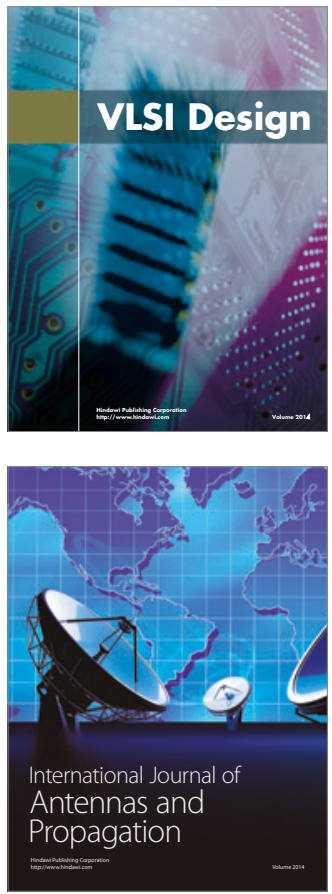

\section{Rotating}

Machinery
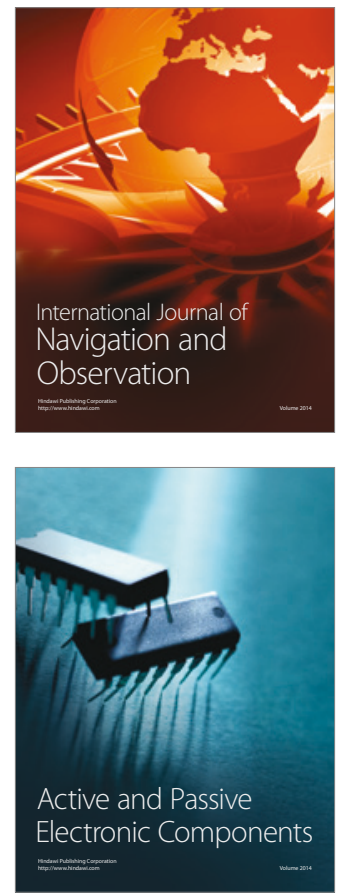
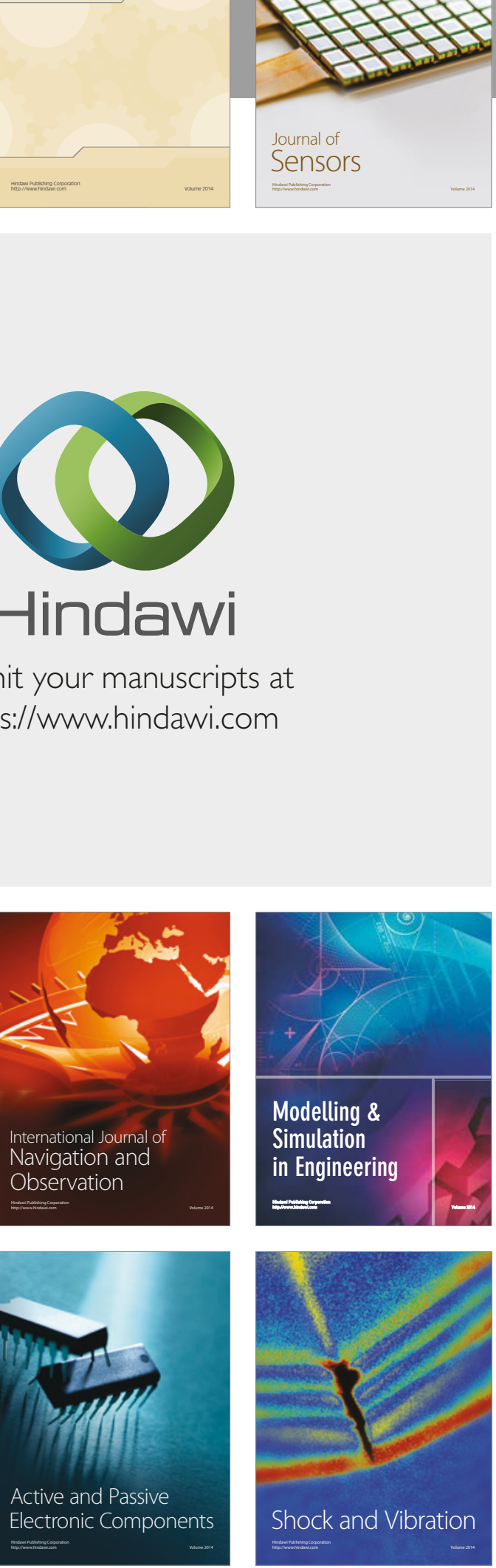
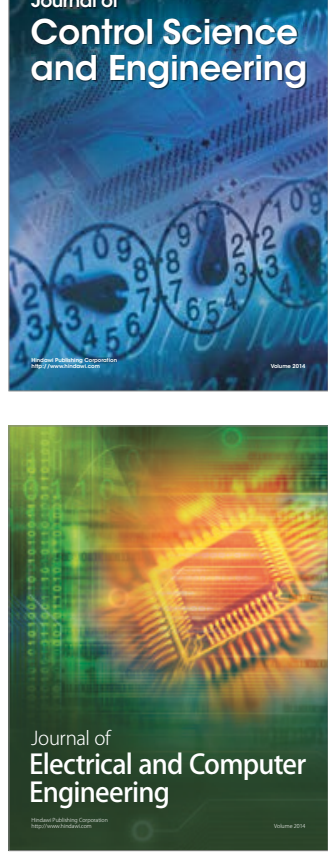

Distributed

Journal of

Control Science

and Engineering
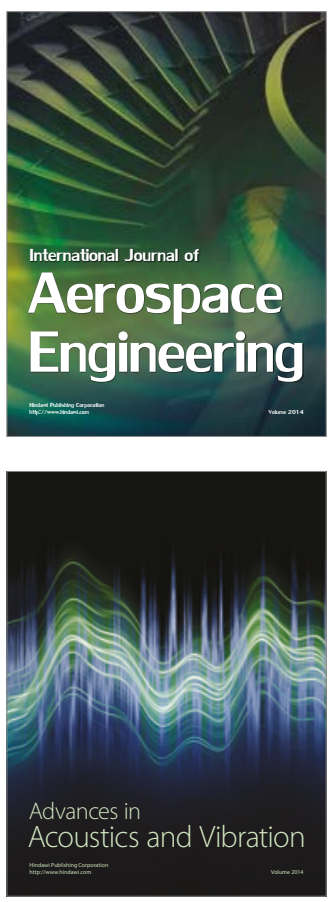

Sensor Networks 